\title{
An Ethics of Care Research Manifesto
}

Tula Brannelly, Bournemouth University

Key words: ethics of care, marginalisation, social research, transformation, participatory

methodologies

\section{Abstract}

Participatory methodologies are frequently used in social research and have matured over the past decades. Ethical aspects of participatory research feature in retrospective accounts of partnerships that contribute to quality research, and those that were problematic to negotiate in the research partnership. Meanwhile, social researchers have shared concerns about meaningful transformations from research and the processes involved to achieve effective, responsive partnerships. As participatory methodologies have matured, so has an ethics of care. An ethics of care research manifesto provides a framework for surfacing marginalisation and potential for transformation, considering interdependencies, and negotiating research relationships with the broader research community.

\section{Introduction}

Participatory approaches are widely adopted in social research and have matured over the past decades to provide numerous approaches to participating with more marginalised communities. This is often, but not always, exploratory qualitative research that has a commitment to social justice by surfacing the inequalities experienced by marginalised groups, with the expectation of influencing political action for change. Effecting change is often the shared motivation for researchers and community partners, and the various participatory methodologies have different approaches to achieve this aim (Edwards and Brannelly, 2017). The broader political research landscape calls for the need for transformations from (social) research, but impact is inadequate when measured against the needs that communities identify as necessary for wellbeing (Barnes, Ward and Gahagan 
2018). Please note that 'participatory methodologies' is an umbrella term used here to cover research that includes partnerships with people who are the focus of that research, including emancipatory methodologies, co-production, and decolonised methodologies. Participants refers to people who co-produce research in partnerships.

As participatory research has matured, so too has the ethics of care emerged as a critical response to neoliberalism, also with a commitment to social justice (Tronto 1993, 2013, 2017, Barnes 2012, Barnes et al 2015). It has been applied to diverse disciplines, and theoretical and applied development continues, in this case to research. An ethics of care has two prongs that 1) surface marginalisation, value relational interdependencies and a broad definition of care, and 2) the integrity of care to guide and review praxis. The integrity of care has five elements (Tronto 1993, 2013):

- Caring about - attentiveness

- Caring for - responsibility

- Care giving - competence

- Care receiving - responsiveness

- Caring with - solidarity

An ethics of care prioritises experiential knowledge. For participatory methodologists, an ethics of care analysis enables a systematic deliberation of the broad political dimensions of research and the intricate relational aspects of research partnerships. All research projects may be reviewed using this framework to articulate and challenge contradictory actions that limit the aspirations of research partnerships, and extend the potential for transformation. In this paper, examples of the ethics of participatory approaches are discussed to highlight recent discussions about the what is considered ethical in participatory research. This discussion draws out the the need for situated, complex understanding of ethics in praxis, and the broader systemic challenges faced by social researchers.

\section{Ethics and participatory methodologies}

Participatory methodologies are likely to be familiar territory to the readers of this journal however, it is worth rehearsing their principles with the caveat that they are contested. Participatory research 
is conceptualised, implemented, analysed, and disseminated in a partnership between researchers and end users of research. End users of research have experience of the focus of the research, and may be service users, care partners, service providers, commissioners, third sector organisations, practitioners and others.

Criticisms of participatory research practices include questions of representation (who contributes), concerns about tokenistic participation (how people are enabled to contribute), and power imbalance (whose knowledge is prioritised, who is paid to contribute) that challenge poor practices (Pickering and Kara 2017, Stenning and Wintrup 2018, forthcoming). Researchers concerned about methods offered for participation have sought increasingly creative solutions to engage people in participatory methods such as song, poems, theatre and dance (Pickering and Kara 2017, Erel, Reynolds and Kaptani 2017). Wykes (2014) identified that although researchers think much progress has been made, participators tend to see progress as slow, with much yet left to do. Despite such limitations, participatory methodologies achieve democratic aims better than other approaches (Edwards and Brannelly 2017), to create partnerships that centralise experience as critical knowledge (Smith 1987).

Researchers routinely negotiate ethical dilemmas and difficulties from the conception of a research project to its end. Whether ethics committees improve the ethics of projects has been challenged (Hammersley 2008), and ethical codes tend to outline basic research premises. Participatory researchers have complex and situated concerns that arise within research relationships and as responses to external stakeholders. Here are a few examples.

What counts as participatory research is an issue. The argument that participatory research yields better quality research (Faulkner 2004) is widely accepted, and integration of experiential knowledge is accepted to the degree that social research funders require evidence that people with experience have been involved in the formulation of research projects. However, how this is 
achieved is variable. For example, consultation would be considered inadequate by participatory methodologists (Fawcett et al 2017).

With the growth in expectation of participation, there is the risk that researchers are unaware of potentially oppressive practices that re-enact marginalisation through tokenistic or under-informed involvement. People who participate in research partnerships have often had previous experiences of participation, for example as co-researchers, who understand the practices of research that value experiential knowledge alongside academic and other forms of knowledge. Hardy et al (2015) offer best practice solutions for building trust with partner communities, acknowledging that the usefulness of community participative approaches is bolstered or diminished depending whether there is trust between the community and researchers.

Concerns about over-researched communities focus on multiple agencies and funders trending toward specific issues, with congregations of researchers soon present in those communities. One concern is that people repeatedly contribute to research projects, when researchers are unaware of simultaneous or previous projects. Neal et al (2015) challenge the negative connotations associated with over-researched communities and suggest that the presence of many researchers builds knowledge and vitalises communities toward research. Participatory methodologies require research capacity building within communities and multiple projects means that communities are better informed about research and potential benefits to communities.

Researchers inhabit an insider/outsider status, using their links and insider knowledge for access to and increased understanding of the community, but with a responsibility to externalise that knowledge to the other worlds. The insider/outsider status has distinct ethical dimensions about revealing aspects of the community to others, and preserving integrity within the community whilst meeting the responsibilities of research. Bozalek (2011) noted that participatory learning action research techniques make it possible to bring people together to confront differential privileges, thus giving people the opportunity to become both insiders and committed outsiders in their 
interactions across differences. Mayorga-Gallo and Horge-Freeman (2017) also consider the 'powerladen particularities of the interaction' by conceptualising credibility and approachability for both the researchers and researched to move beyond simplistic characterisations of the insider/outsider status.

Participation in research projects hinges on criteria for inclusion that superficially represent identity, and positions people to draw primarily on that identity whilst ignoring or excluding other aspects of their selves. A service user may also be an academic, a caregiver and a care receiver (Ward 2011). Research relationships with people are needed to understand the multiple positions from which they can contribute.

Researchers are aware that change is necessary in researched communities, but are often unable to offer guarantees of change as a result of participation. Relief from poor conditions that influence wellbeing is a clear reason why people agree to collaborate as partners in research. However, impact is not solely focused on or prioritised as improving wellbeing of communities. It is conceptualised as academic - influencing theory, and societal - influencing practice (see the Economic and Social Research Council (ESRC) impact toolkit). Academic impact includes developments in theory and method, and societal impacts include capacity building and instrumental change. The ESRC encourages researchers to use the toolkit to plan for impact from research, including knowledge exchange activities as part of research projects. Participatory methodology partnerships develop understanding about knowledge exchange and impact as projects progress, with negotiation about what constitutes impact and who may lead knowledge exchange. The emphasis remains on what matters to the community.

In the next section, an ethics of care research manifesto is introduced that embraces a care-based methodology with the intention of beginning a debate about what appears in such a manifesto. A sweep of the literature was undertaken that searched for ethics of care and research methodologies literature from 2010, and relevant ethic of care theory adapted to research. 


\section{An ethics of care research manifesto}

An ethics of care research manifesto is firmly rooted in feminist theory, and calls for surfacing of marginalisation, and equality to be addressed (Tronto 1993, 2013, 2015, 2017), responsibility to create change, analysis of care practices (Sevenhuijsen 1998, 2014, Barnes 2006, 2012), deliberating with care for solidarity with marginalised groups (Barnes, 2012, Barnes et al 2015, Barnes, Gahagan and Ward 2018), through inextricable interdependencies (Kittay 2015). Understanding that humans are interdependent and relational, that care requires the knowledge of the context and detailed understanding of need, and that this can only be known if the experiences of people who are marginalised is understood is fundamental to action orientated responsibility. Research is a social practice; embedded into the integrity of care, it is possible to elucidate how research could be practiced according to these dimensions.

Integral to the ethics of care maturity process is that theorists have sought common ground. Engster and Hamington (2015) proposed five shared aspects.

- Interdependence was noted as the relational approach to morality.

- Responsiveness to the other is important to theorists including Tronto and Kittay.

- Care in context challenges distanced and removed abstracted moral theory.

- Care as political, recognises its feminist roots.

- And emotions count, which challenges traditional moral theory.

Collins (2015) produced a slogan for the ethic of care - dependency relationships generate responsibilities. The distinctiveness of the ethic of care, and its greatest strength is in its political feminist roots (Robinson 2015, p293), toward social justice by recognition and responsibility to produce change.

Tronto (2015) reminds us that care can offer a different analysis to more traditional forms of social science, to move on from documentation of social issues to take responsibility for change, thereby integrating care into social science paradigms. Distanced positions are not adequate to understand context, appreciate interdependencies or take responsibility (Tronto, ibid). Sayer (2011) identifies that social scientists remove normative meaning from what matters to people in the academic process of abstracting to theory, with the consequence that what matters to people is edited out of 
academic discourse. This is unlikely to encourage people to contribute to research. Research informed by an ethic of care values:

- Longer-term responsive partnerships with communities;

- Enabling participation of marginalised groups; researchers retain responsibility for enabling communities to voice dissatisfactions to inform directions for change;

- Participation from the multiple positions and identities people inhabit in their lives, moving away from the bureaucratic compartmentalising approach. This is only possible by relational connection creating space for discussion and deliberation;

- Careful research practices that consider the experience of participation and takes the time to examine research practices with participants.;

- Identification of the need for locally produced action to achieve change that is co-negotiated with participants.

\section{Marginalisation and addressing inequality}

Social researchers are interested in how people are marginalised and the effects of inequality on groups of people, and how this is experienced. An aim of research is recognition of the conditions and positioning of specific groups, and is of itself, a political and moral action. Adopting an ethics of care manifesto, extends recognition to responsibility, which would frame research projects differently to create opportunities for real life change.

Foregrounding giving and receiving care as essential to the human condition, offers a substantial basis and a shared moral language from which to build social policies (Robinson 2015, Barnes and Brannelly 2008). Robinson (2015) warns us to expect that there is no great revolution, but a slow, plodding journey to transformation. A reasonable explanation for why participatory methodologies have not attained transformational potential is that the extension from recognition and critique to action has not been realised. 
Blazek et al (2015) recognised that the impacts of research cannot always be planned, but that an ethic of care 'embedded in relationships within and beyond research settings may form conditions in which outcomes exceeding the initial expectations can be anticipated' (pg 45), thus making research projects 'more than research' by creating opportunities for transformation. Sasser (2014) recognises that researchers would like to reciprocate with the communities in which they research. Hanrahan (2015) renewed livelihoods policy in Africa to acknowledge relational care and its impact on economic sustainability in response to the community who contributed to the research.

\section{Inextricable interdependencies}

Inextricable interdependencies (Kittay 2015) acknowledges the significance of relationships, and the extent to which researchers are involved in the communities where they research. An ethic of care approach values longer-term ongoing relationships over time that builds a collaborative approach, but which also is led by the needs and wishes of that community. Several research projects have explicitly used an ethic of care as part of their methodology. Barnes, Gahagan and Ward (2018) used an ethics of care approach to understand older people's experiences and conceptualisations of wellbeing and care (Ward and Gahagan 2010, Ward and Barnes 2016). These projects collaborated over many years with a group of older people through a third sector organisation, Age UK. Ward and Barnes (2016) reflected on their reflective spaces for transformative dialogue.

A collaborative approach developed a relational definition of wellbeing (Barnes, Gahagan and Ward 2018). The older people in the project described how troubled relationships influenced wellbeing, and that positive relationships were necessary for wellbeing. Herron and Skinner (2013) used the principles of contextual sensitivity, responsiveness and attentiveness to inform their research approach with older people in rural Canada, and found that it enabled more inclusive understandings of vulnerability within that population. Herron drew on her insider knowledge having grown up on a farm as a starting point to relate to the farmwomen in the study, which enabled greater inclusion of their conceptualisations of vulnerability. They note the potential that 
care ethics (Hankivsky 2004) has on research processes for enhanced connection, participation and negotiation.

Hospitality is an openness through kindness that welcomes, to accept what the other brings, a wish to hear the voice of the other, a space created to do so, to make the other feel wanted and thought of as important. Māori create new connections through hospitality and sharing ancestral links, no matter how distant temporaneously or spatially (Brannelly, Boulton and Ti Hiini 2011). Hospitality opens an opportunity to build 'mana' or prestige. As Gouws and van Zyl (2015 p173) explain about ubuntu in African culture, it is that 'people are bound together in relations of mutual respect and dignity where one's humanity is diminished by acts of greed or deeds of oppression'. In Māori culture, and adopted more widely in Aotearoa New Zealand, it is imperative to understand who is in the room, and what possible connections and history people bring to the encounter.

\section{Deliberative approaches for solidarity}

Barnes (2012) reminds us that it is deliberative and participatory processes that facilitate recognition and exchanges that lead to transformations. An emphasis on experience rather than the defining feature that prompts that experience, 'destabilises the processes by which people are defined as different, for example as having a diagnosis of mental illness consistent with Fraser's reconsiderations of the centrality of the politics of difference' (Barnes 2012 p115,). Fraser (2000 p119) states:

...today's struggles for recognition often assume the guise of identity politics. Aimed at countering demeaning cultural representations of subordinated groups, they abstract misrecognition from its institutional matrix and sever its links with political economy and insofar as they propound 'authentic' collective identities, serve less to foster interaction across differences than to enforce separatism, conformism and intolerance.

Brown (2018, forthcoming) highlights the problems with this approach in a classroom setting when the identification of one set of people as experts by experience, such as mental health service users, produces artificial categorisations which act to deny the voices of others. Brown (ibid) points out that these artificial boundaries silence people rather than opening a discussion about how mental distress affects everybody. Duncan and Stephenson (2013) recognise that for more productive 
research discussions, participants and researchers have both responsibilities and vulnerabilities to share power to avoid artificial subject positions. Johnson and Martínez Guzmán (2014) suggest that researchers 'consider naturalized social definitions of who is vulnerable or marginalized as both the object and field of social transformation' (p417, their emphasis). The ethics of care would urge us to avoid the pitfall of creating difference through such artificial categorisations, instead offering participants and researchers openness and generosity.

Knowledge production is enhanced by encouraging open discussions and valuing diverse contributions that acknowledge intersectionality. Tronto (1993), Bourgault (2016) and Sevenhuijsen (2014) refer to Simone Weil's identification of 'attention as the purest form of generosity'. In attending to the voices of people who express experiences of oppressions, discriminations and harms endured, attentive listening requires that the listener is open and vulnerable (Bourgault 2016). Responsiveness is required by the listener that demonstrates awareness of the inference of the interaction in that moment, that make apparent the varied positions that contributors inhabit and lead to meaningful explorations and discussion of the issue. Informed by the ethic of care, this careful deliberation upholds and emboldens trust and solidarity, or threatens it. Bourgault (2016) also reminds us that responsiveness can be shared as a collective action.

Sevenhuijsen (2014) recognises that many political situations require careful attention to find solutions that remedy the situation. Participatory and deliberative approaches to public housing, for example, to discuss design decisions would avoid the existence of many forms of poor public housing. Attentive activities include presence, seeing, careful and active listening, thoughtful speaking, recognition of plurality and accountability (Sevenhuijsen 2014). Sevenhuijsen (ibid) suggests thoughtful speaking can reduce blockages in attentive interactions. While thoughtful speaking is desirable, there is a need to be attentive to the position that people may find thoughtful speaking difficult, such is the emotional content and dissatisfaction they feel. Voices may be frail, or for good reason, confrontational (Barnes et al 2015). 
Bourgault (2016) reminds us that the listener may not be accustomed to the voices presented to them, requiring time and space to accommodate difference. Bourgault (ibid) and Barnes et al (2015) call for the listeners to retain the responsibility to listen, however the voice is presented. Reissman (2007) reminds us that narratives are whatever the speaker wants them to be, however articulate or considered and in whatever way they are delivered. It may be that people are offered creative methods of engagement that relieve the pressure of performance and coherence, for example in research with people with dementia that accommodates cognitive impairments. Terkel and Larsen (2016) used an ethic of care dialogic framework and found that it transformed understanding between staff and service users on psychiatric wards in Norway. In discussions of fear and violence, the focus shifted to experience, rather than to entrench and reinforce dichotomous positions of perpetrators and victims of violence.

Listening forms part of attentiveness, and Bourgault suggests that the importance of active listening is underappreciated an ethics of care. Sevenhuijsen (2014) and Bourgault (2016) identify how easily attentiveness is disrupted, a propensity for distraction that seems inevitable in increasingly digitallyfocussed world in hurried times (Bourgault 2016). Listening enables acknowledgement, recognition and attention. Not being listened to is a form of epistemological violence, an act of power that is an affront to the person who is ignored, and a source of great frustration (Teo, 2010) As Bourgault suggests, it is the onus on the powerful to attend to hearing the voice of others.

\section{Analysis of careful research practices,}

Careful research practices are guided, revised, analysed, and evaluated using the integrity of care

(Tronto 1993, 2013):

- Attentiveness

- Responsibility

- Competence

- Responsiveness

- Solidarity.

In the previous section on deliberative participation, attentiveness and responsiveness were discussed, for attentive listening and responses that build trust and solidarity. Responsibility in the 
research process is reflexive responses to communities that recognise and act on need. Researchers have access to information, resources and connections through which change may be initiated. Responses that indicate unwillingness to engage outside of the research protocol are likely to break trust.

Researchers develop the skills and knowledge for participatory methods and capacity building within research is necessary. Creating and sustaining positive research relationships is considered advanced research practice, and capacity building with earlier career researchers would enable sustainability. Competent researchers understand dynamics of engagement and skilled facilitation, and the interpersonal skills needed to establish good relationships, and more importantly, to evaluate their direction of travel. These are skills that emerge by doing and develop in praxis. Supervision and access to support enables researchers to engage with the vulnerabilities required for meaningful participation. Responsiveness and solidarity are instrumental in understanding how external requirements impact on the relational quality of participatory work. How will the community respond to this request, or does this create a tension with the aims of the community are good indicators of the responses that research incorporate into external discussions.

Kuis, Hesselink and Goossensen's (2014) ethic of care conceptual framework for evaluation of care quality is adaptable to research as it resonates with how people involved in participatory research projects respond. Their framework includes the reflective qualities of the researcher, a positive collaboration, searching for the logic - understanding the root of the issue from its beginnings and how it influences current thinking and being, feeling understood, and decreased loneliness. People who contribute to collaborative research partnerships report similar impacts whereby people feel listened to and part of something that may be influential. In a recent research project, people with dementia commented that the chance to contribute to a collaborative research partnership offered hope for a different future (Bartlett and Brannelly 2018). 
Researchers can also consider how the integrity of care is bolstered by methodological approaches. Visse and Niemeijer (2016) identify that auto-ethnography lends itself to care in the research process due to its stronger emphasis on what matters to people, what they care about, rather than what is 'right', illustrating the need for contextualised research that connects with the morality of those effected by the issues under investigation. Narrative approaches (Reissman 2007) provide the openness required for deliberation.

\section{Conclusion}

In summary, the ethic of care research manifesto values longer-term involvement with communities that is respectful to the communities needs and wishes. The experience of marginalisation and exclusion may be communicated in a myriad of ways and researchers retain some responsibility for enabling communities to voice dissatisfactions and take from that the directions for change. Recognising need and marginalisation encourages expression from the multiple positions and identities people inhabit in their lives. A move away from the bureaucratic compartmentalising approach is achieved through relationships and creating deliberative space. Careful research practices consider the experience of participation and takes the time to examine research practices with participants and coresearchers. And finally, researchers create research proposals that identify the need for local action to achieve change that is co-negotiated with participants and coresearchers, and draw on the considerable resources that they have access to through their institutions.

Participative approaches are challenged by institutional mores. These include funding availability, favoured methodologies, recognition of participation rather than inclusion or consultation with participants, flexibility for participative methodologies to develop projects in partnerships considered high risk for some funders, and ethics committees understanding and support for participative methodologies. An ethics of care research manifesto centralises care in research methodology and frames philosophical knowledge to respond to such challenges. New(-ly 
encouraged) research practices such as knowledge exchange and impact require critical analysis of what knowledge and impact is privileged.

The impetus for the ethics of care research manifesto is a response to the need for a more systematic approach to considering the ethics of participatory methodologies. To more fully appreciate the impacts of colonisation and potential for recolonization through research practices in Aotearoa New Zealand, it was the ethics of care that informed more sensitive and careful approaches to try to avoid marginalisation and oppression (Brannelly and Boulton 2017). Within that partnership it was vital to understand consequences of colonisation in terms of historical harms, and research subjects' experiences of oppression (Smith 2005).

Service user involvement and co-production to influence policy, practice and research emerged as political action out of the global mental health service user movement. The slogan, nothing about us without us was a clear call for participation, neatly sidestepping the harms and oppressions that provoked the call in the first place. Despite rhetorical attempts to improve the lives of people with mental health problems, minimal change has been achieved to make a difference in people's lives because of systematic injustices of unemployment, forced treatment and compulsion, poverty and hardship (Brannelly 2015). An unwillingness to shift societal values means that some people who experience mental health problems continue to be condemned to poverty, poor housing and multiple social exclusions. These exclusions have been evidenced through social research.

Action that makes a difference can only be achieved with experiential knowledge leading transformation; Robinsons' (2015) revolution in slow, plodding steps. The barriers and limitations to potential transformations are confined within cultures and systems that deter progress, and the ethics of care enables identification of these processes and systems which sustain marginalisation. This framing of social research offers the opportunity to review the purpose, intent and consequences of research on communities, for a nuanced, complex and situated evaluation that 
values, above all, the lived experience and real-life change that improves the conditions of life by addressing what matters to people. 


\section{References}

Barnes, M. and Brannelly T., (2008). Achieving care and social justice for people with dementia. Nursing Ethics, 15 (3), 384-395.

Barnes, M., Brannelly T., Ward, L. and Ward, N., (2015). Ethics of care: Critical advances in international perspective, Bristol: Policy Press.

Barnes M., Gahagan B., and Ward L., (2018) Re-Imagining Old Age, Wellbeing, Care and Participation, Malaga, Vernon Press.

Bartlett R. and Brannelly T., (2018), Life at Home for People with a Dementia, London: Routledge.

Blazek M., Smith F.M., Lemešova M., Hricova P., (2015), Ethics of care across professional and everyday positionalities: The (un)expected impacts of participatory video with young female carers in Slovakia, Geoforum, 61, 45-55, doi: 10.1016/j.geoforum.2015.02.017.

Bourgault S., (2016) Attentive listening and care in a neoliberal era: Weilian insights for hurried times, Ethics and Politics, XVIII, 3, $311-377$.

Bozalek V (2011) Acknowledging privilege through encounters with difference: Participatory Learning and Action techniques for decolonising methodologies in Southern contexts, International Journal of Social Research Methodology, 14, 6: Perspectives on decolonising methodologies

Brannelly T., and Boulton, A., (2017) The ethics of care and transformational research practices in Aotearoa New Zealand. Qualitative Research, 17 (3), 340-350.

Brannelly T., (2015), Mental health service use and the ethics of care: In pursuit of justice, in Barnes, M., Brannelly T., Ward, L. and Ward, N., (2015). Ethics of care: Critical advances in international perspective, Bristol: Policy Press.

Brown J., (2018), 'Dilemmas of disclosure in mental health therapeutic education', in Wintrup J, Biggs $\mathrm{H}$, Brannelly T., Fenwick A., Ingham A. and Woods D., (Eds) Ethics from the ground up: emerging debates, changing practices and new voices in healthcare, London: Palgrave Macmillan.

Collins S., (2015), The Core of Care Ethics, London: Palgrave Macmillan.

Economic and Social Research Council https://esrc.ukri.org/research/impact-toolkit/what-is-impact/

Edwards, R. and Brannelly T., (2017), Approaches to democratising qualitative research methods. Qualitative Research, 17 (3), 271-277.

Engster D. and Hamington M., (2015), Care Ethics and Political Theory, Oxford Scholarship Online.

Erel U, Reynolds T and Kaptani E (2017), Participatory theatre for transformative social research, Qualitative Research, Vol. 17(3) 302-312, DOI: 10.1177/1468794117696029

Fawcett B., Fillingham J., River D., Smoijkis M., Ward N. (2017), Service user and carer involvement in health and social care: a retrospective and prospective analysis, London: Palgrave Macmillan.

Fraser N., (2000), Rethinking Recognition, New Left Review, 3, 107 - 120.

Gouws A. and van Zyl M., (2015) Towards a feminist ethics of ubuntu, bridging rights and ubuntu, in Engster D. and Hamington M., (2015) Care Ethics and Political Theory, Oxford Scholarship Online, DOI: 10.1093/acprof:oso/9780198716341.003.0010.

Hammersley M., (2008) Against the ethicists: on the evils of ethical regulation, International Journal of Social Research Methodology, 12, 3, doi.org/10.1080/13645570802170288 
Hankivsky, O. (2004). Social policy and the ethic of care. Vancouver, BC, Canada: UBC Press.

Hanrahan K.B., (2015) Living Care-Fully: The Potential for an Ethics of Care in Livelihoods Approaches, World Development Vol. 72, pp. 381-393, doi.org/10.1016/j.worlddev.2015.03.014

Hardy L., Hughes A., Hullen E., Figueroa A, Evans C., Cruz Begay R., (2015) Hiring the experts: best practices for community-engaged research, Qualitative Research, 16 issue: 5, page(s): 592-600, doi.org/10.1177/1468794115579474

Herron R.V and Skinner M.W., (2013), Using Care Ethics to Enhance Qualitative Research on Rural Aging and Care, Qualitative Health Research, 23(12) 1697-1707, DOI: 10.1177/1049732313509893

Johnson K. and Martínez Guzmán A., (2014) Rethinking Concepts in Participatory Action Research and Their Potential for Social Transformation: Post-structuralist Informed Methodological Reflections from LGBT and Trans-Collective Projects, Journal of Community \& Applied Social Psychology, 23: 405-419 (2013) DOI: 10.1002/casp.2134

Kittay R.F., (2015) A theory of justice as fair terms of social life given our inevitable dependency and our inextricable interdependency, in Engster D and Hamington M (2015), Care Ethics and Political Theory, Oxford Scholarship Online, DOI: 10.1093/acprof:oso/9780198716341.001.0001

Kuis E., Hesselink G. and Goossensen A., (2014), Can quality from a care ethical perspective be assessed? A review, Nursing Ethics, Vol. 21(7) 774-793 DOI: 10.1177/0969733013500163

Neal S., Mohan G., Cochrane G., Bennett K. (2015) 'You can't move in Hackney without bumping into an anthropologist': why certain places attract research attention, Qualitative Research, 16 issue: 5, page(s): 491-507, doi.org/10.1177/1468794115596217

Pickering L., Kara H., (2017), Presenting and representing others: towards an ethics of engagement, International Journal of Social Research Methodology , 20,3: doi.org/10.1080/13645579.2017.1287875

Reissman C.K., (2007), Narrative Methods for the Human Sciences, Sage: California.

Robinson F., (2015) Care ethics, feminism and the future of feminism, in Engster D and Hamington M (2015), Care Ethics and Political Theory, Oxford Scholarship Online, DOI: 10.1093/acprof:oso/9780198716341.003.0016

Sasser J.S. (2014), The Limits to Giving Back, Journal of Research Practice, 10, 2, article M7.

Sayer A., (2011), Why Things Matter to People - Social Science, Values and Ethical Life, Cambridge: Cambridge University Press.

Sevenhuijsen S., (2014) 'Care and attention', paper presented for the conference $A$ meaningful life in a just society. Investigating wellbeing and democratic caring. Panel - Rendering care the meaning of politics, Utrecht, Universitiet voor Humanistiek, 30 - 31 January 2014.

Smith D.E., (1987) The Everyday World as Problematic: A Feminist Sociology, Milton Keynes: Open university Press.

Smith L.T. (2005) On tricky ground, researching the native in the age of uncertainty. In Denzin NK and Lincoln YS (eds) The SAGE Handbook of Qualitative Research. Thousand Oaks: SAGE.

Stenning D. and Wintrup J., (2018, forthcoming) 'Patients as leaders: reflections on identity, equality and power', in Wintrup J, Biggs H, Brannelly T, Fenwick A, Ingham A and Woods D (Eds) Ethics from the ground up: emerging debates, changing practices and new voices in healthcare, London: Palgrave Macmillan. 
Teo T., (2010), What is Epistemological Violence in the Empirical Social Sciences? Social and Personality Psychology Compass, 4: 295-303. doi:10.1111/j.1751-9004.2010.00265.x

Terkel T.B. and Larsen I.B., (2016), Fear, danger and aggression in a Norwegian locked psychiatric ward: Dialogue and ethics of care as contributions to combating difficult situations. Nursing Ethics, Vol. 23(3) 308-317, DOI: 10.1177/0969733014564104.

Tronto JC. (1993), Moral Boundaries, a political argument for an ethic of care, New York University Press, New York.

Tronto JC. (2013), Caring Democracy, New York University Press, New York.

Tronto J.C., (2015) Theories of care as a challenge to Weberian paradigms in social science, in Engster D and Hamington M (2015), Care Ethics and Political Theory, Oxford Scholarship Online, DOI: 10.1093/acprof:oso/9780198716341.003.0014

Tronto J.C., (2017), There is an alternative: homines curans and the limits of neoliberalism, International Journal of Care and Caring, Vol 1, 1, pg 27-43, doi.org/10.1332/239788217X14866281687583

Visse M. and Niemeijer A., (2016) Autoethnography as a praxis of care - the promises and pitfalls of autoethnography as a commitment to care, Qualitative Research Journal, Vol. 16 Iss 3 pp. $301-312$ doi.org/10.1108/QRJ-04-2016-0021

Ward L. and Barnes M., (2016), Transforming practice with older people through an ethic of care, British Journal of Social Work, 46, 906 - 922, DOI: 10.1093/bjsw/bcv029

Ward L. and Gahagan B., (2010), Crossing the Divide between Theory and Practice: Research and an Ethic of Care, Ethics and Social Welfare, 4, 2, DOI: 10.1080/17496535.2010.484264

Ward N., (2011), Care Ethics and Carers with Learning Disabilities: A Challenge to Dependence and Paternalism, Ethics and Social Welfare, 5(2), 168-180, DOI: 10.1080/17496535.2011.571066

Wykes T., (2014) Great expectations for participatory research: what have we achieved in the last ten years? World Psychiatry Volume 13, Issue 1, pages 24-27, February 2014, DOI:

10.1002/wps.20086

\section{Acknowledgement}

Thanks to Maurice Hammington for the invitation to contribute this article and for comments on an earlier version. Tula Brannelly and Marian Barnes presented a panel at the Economic and Social Research Council Research Methods Festival, June 2018 on Beyond participatory methods - a call for the ethics of care https://www.ncrm.ac.uk/RMF2018/programme/session.php?id=D8 